| Journal of Applied Business Research - First Quarter-2006

Volume 22, Number

$\underline{1}$

\title{
Discontinued Operations Recognition, Initial Provisions, And Subsequent Adjustments
}

Allison Collins, (Email: collinsa@memphis.edu), University of Memphis Denton Collins, (Email: dlcollin@memphis.edu), University of Memphis

\begin{abstract}
This study extends our understanding of why firms choose to take discretionary write-offs and identifies factors that influence the measurement of the charges taken. We focus on segment disposals, initial provisions recorded upon discontinuance of those segments, and adjustments to initial provisions that accompany the segment disposals. We partition our sample into those disposals that were substantially completed at the time of recognition (nondiscretionary disposals) and those that were recognized prior to disposal completion (discretionary disposals). With respect to motivations for taking discretionary rather than nondiscretionary disposals, we find that firms electing discretionary disposals discontinue segments that experience sharp declines in earnings and that require more negative initial provisions; the continuing portion of these firms are less profitable and are in weaker financial condition when compared to firms recognizing disposals upon completion. Further, they are more likely to announce the disposal in the fourth quarter, and they are more likely to underestimate the cost of disposal. With respect to measurement issues, we find that subsequent adjustments to initial provisions for discretionary disposals relate both to firms' abilities to estimate losses on disposal at the plan date and to management incentives to manage disclosures. In contrast, subsequent adjustments accompanying nondiscretionary disposals relate primarily to uncertainties contained in the disposal agreement.
\end{abstract}

\subsection{INTRODUCTION AND SYNOPSIS}

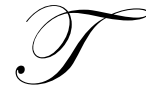

he purpose of this study is to extend our understanding of why firms choose to take discretionary write-offs and to identify factors that might influence whether a write-off is miss-measured (i.e., whether a recorded write-off or provision is excessive or inadequate). On September 28, 1998, Chairman Arthur Levitt of the Securities and Exchange Commission delivered a speech at the NYU Center for Law and Business in which he expressed his concern that "we are witnessing an erosion in the quality of earnings, and, therefore, the quality of financial reporting." One concern he raised is the temptation faced by firms to overstate restructuring charges in an effort to "clean up" their balance sheets (Levitt 1998). While prior research has documented a tendency of some firms to record multiple write-offs over time (e.g., Elliott and Hanna 1996), relatively little work has been published documenting the extent to which specific write-offs are overstated or understated. To our knowledge, the only extant research examining adjustments to specific write-offs and whether these adjustments represent earnings/balance sheet management is by Moerhle (2002). Two factors may be at play in this relative lack of published research. First, relatively few firms disclose adjustments to initial provisions or provide adequate detail for empirical investigation, which can make empirical examination difficult. ${ }^{1}$ Second, once an asset remaining in use has been written down in value, U. S. accounting standards essentially prohibit firms from writing those assets back up to a higher carrying value. The implication is that, under U. S. GAAP, upward revaluations of assets that remain in use by firms are rare or nonexistent. These two factors impose significant barriers to more detailed empirical studies of these "excessive" write-offs. To overcome some of these disclosure limitations, we focus instead on segment disposals (or discontinued operations). 
Segment disposals are special forms of restructuring charges that possess several characteristics that allow the implementation of better controls in addressing measurement issues relating to whether initial provisions are inadequate or excessive. First, segment disposals, or discontinued operations, are non-recurring asset write-offs that recognize the discontinuance of complete divisions or lines of business. Accounting standards require that provisions for gains or losses on disposal and the prior operating performance of discontinued operations be reported separately from continuing operations (on an after-tax basis). Second, later adjustments (either gains or losses) to initial provisions accompanying segment disposals are also reported separately from continuing earnings, providing us with a proxy for the degree of error in any initial estimates. Finally, although adoption of a plan for disposal of a segment triggers accounting recognition, a firm has significant leeway in choosing when to adopt such a plan. Plan adoption (with subsequent accounting recognition) can occur at a preliminary stage prior to the commencement of actual disposal activities (a "discretionary" disposal) or it may be delayed until the actual disposal transaction is essentially completed (a "nondiscretionary" disposal).

"Discretionary" segment disposals force firms to confront measurement issues that differ from those associated with "nondiscretionary" disposals. Specifically, reported initial provisions associated with discretionary disposal recognition primarily reflect managers' estimates of the costs and expenses of disposal actions to be undertaken by firms in the future. In this respect, discretionary segment disposals share some characteristics with "above-the-line" restructuring charges that involve asset disposals and capacity rationalizations, in that both reflect estimates of the costs and expenses of actions yet to be completed. In contrast, reported gains or losses associated with "nondiscretionary" segment disposals represent primarily realizations of actions previously undertaken (since disposal is essentially completed). This distinction is important because it allows us to assess the influence of segment-level and firm-level attributes on the measurement of initial provisions and to better characterize the nature of any adjustments arising from initial provisions.

Two reporting and disclosure issues arise from the accounting treatment of segment disposals. First, why would a firm choose to adopt and announce a plan of disposal before the disposition is completed? Prior research has suggested that firms may manage earnings through the reclassification of gains and losses (e.g., Rapaciolli and Schiff 1991; Loh, Hoe and Wilkins 2001), but the question we attempt to answer hints at strategic management of plan adoption timing. Answering the first question will further our understanding of the motivations underlying firms' discretionary accounting choices. Second, what factors explain subsequent adjustments to the initial estimate? In other words, do adjustments to initial provisions accompanying discretionary disposals arise because of some systematic measurement error in initial provisions, or do they arise from strategic incentives to manage financial statement disclosures and the magnitude of any reported provision on disposal (Wilson 1996)? Answering the second question would allow us to provide more direct evidence to assess standard setters' and regulators' concerns about whether and when firms might systematically manage the magnitude of restructuring charges.

To provide evidence on the first question, we profile firms electing discretionary and nondiscretionary disposals and estimate a binary choice regression model of the announcement timing decision. We find that firms electing discretionary disposals are discontinuing segments that require relatively more negative initial provisions, and segments that experience relatively large declines in earnings in the year of discontinuance. With respect to firm-level attributes, we find that firms electing discretionary disposals tend to experience relatively lower levels of continuing earnings, suffer more negative changes in continuing earnings, and have higher debt levels than firms recognizing nondiscretionary disposals. Further, a higher proportion of discretionary disposals occur in the fourth quarter, which suggests that firms undertaking the reclassification prior to consummation of the disposal may be timing their announcements to manage the impact of the reclassification on continuing earnings. These findings are consistent with the prior research on the timing of restructuring announcements and with prior research suggesting that early announcement of accounting events is associated with "bad news" (e.g., Bartov, Lindahl, and Ricks 1998). We also find that firms electing discretionary disposals are more likely to underestimate the cost of disposal than those electing a nondiscretionary disposal.

With respect to the second question, we estimate a regression model of subsequent adjustments in which we incorporate (1) proxies for potential sources of errors in measurements of initial provisions and (2) proxies for managers' motivations to over- or under-estimate the initial provision. For discretionary disposals, subsequent 
adjustments to initial provisions are found to relate both to firms' ability to estimate losses on disposal at the plan date and to management incentives to manage disclosures. Specifically, subsequent adjustments are related to the size of the initial provision and the prior and future performance of the segment, and we find that subsequent adjustments are more positive and less negative when firms changed top management in either the year before or year of the initial write-off and when firms' continuing earnings performance is extreme. These results are consistent with incoming managers taking excessive write-offs and with firms overstating write-offs when earnings performance is extreme. In contrast, subsequent adjustments to nondiscretionary disposals relate primarily to remaining uncertainties that are present at the balance sheet date and do not generally relate to factors implicated in previous research as giving rise to incentives to manage earnings.

The remainder of our paper is organized as follows. Section 2 reviews the accounting treatment of segment disposals. Section 3 describes our sample and section 4 presents the results of our tests of disposal announcement timing. Section 5 considers the potential determinants of the subsequent adjustment phenomenon, defines our proxies for these determinants, describes our model, and presents our regression results, while section 6 describes our sensitivity tests. Finally, section 7 discusses the findings and implications of the research.

\subsection{THE ACCOUNTING TREATMENT OF DISCONTINUED OPERATIONS}

Under Accounting Principles Board Opinion No. 30 (hereafter APB 30; AICPA 1973), accounting recognition of a segment disposal was triggered by a firm's adoption of a plan to dispose of the segment. ${ }^{2}$ A disposal can involve a sale (or spin-off) of all or some part of the segment, and/or phase-out and shut-down of segment operations. For discretionary disposals, APB 30 required two calculations on the date that the plan is adopted (the measurement date). First, the firm was required to estimate any segment income or loss on operations during an assumed disposal period of one year or less. ${ }^{3}$ Second, the firm was required to estimate the gain or loss on revaluation of the segment assets to net realizable value. The sum of these two estimates represented the anticipated gain or loss on disposal of the segment. An estimated overall gain was usually required to be deferred to the period when disposal was essentially complete, while an estimated overall loss was recognized in the current period. For nondiscretionary disposals, realized gains or losses associated with completed disposals were to be recognized in the current period, and additional provisions were to be recognized for any remaining contingencies.

APB 30 also required that the segment's current year operating results up to the date of write-off and its prior year operating results both be reclassified to income (loss) from discontinued operations for all years presented. These results were reported, net of tax effects, below income from continuing operations and above any provision recognized as gain or loss on disposal of the segment. Subsequent adjustments (if any) to initial provisions were treated as changes in accounting estimates and disclosed separately as gains or losses on disposal of discontinued operations in the period the change in estimate occurs or when the transaction is complete. ${ }^{4}$ Examples of some of the footnote disclosures associated with such adjustments are given in Appendix A, while Exhibit 1 provides an example of the income statement presentation of both initial segment disposal announcements and subsequent adjustments to those announcements.

\subsection{SAMPLE SELECTION PROCESS}

| We identify two samples of firms to address the issues raised above. A firm is included in a sample of 4 discretionary segment disposals if it met three requirements. First, the firm reclassified the operations of the segment at the time it disclosed a plan to discontinue that segment. ${ }^{5}$ Second, the firm completed the disposal of the segment in an accounting year subsequent to the announcement year. Third, the firm disclosed sufficient information to allow tracking the transaction until disposal was essentially complete, to determine segment earnings, and to determine whether any subsequent adjustments were made to the initial provision. A firm is included in a sample of nondiscretionary segment disposals if (1) the disposal was essentially completed as of the balance sheet date or if a definitive sales contract for the segment was in effect in the announcement year and (2) disclosure was comparable to that specified for discretionary disposals. ${ }^{6}$ We define a subsequent adjustment as any loss or gain adjustment that is specifically associated with an initial provision and that occurs up to two years after the initial disclosure. 
To maintain consistency across time with prior studies, we select an initial sample of firms from the 1983 1990 period. A total of 648 firms disclosing discontinued operations were identified in the 1990 Annual Report file in the NAARS database. Of these, 295 firms were excluded due to inadequate disclosure or missing financial statements, 42 firms whose segments were spun-off, 13 firms that had declared bankruptcy or whose discontinued segments were in bankruptcy proceedings, 11 firms that did not discontinue a segment, nine firms that reversed their decision to discontinue their segment, six firms involved in quasi-reorganizations, and three firms whose annual reports were duplicates. This left a sample of 143 firms reporting discretionary disposals and 126 firms reporting nondiscretionary disposals. Of the 143 firms reporting discretionary disposals, 48 firms reported no adjustment to their initial provision, 34 reported subsequent gain adjustments, and 61 reported subsequent loss adjustments. Of the 126 firms reporting nondiscretionary disposals, we observe 82 reporting no adjustment to their initial provision, 26 reporting subsequent gain adjustments, and 18 reporting subsequent loss adjustments. These patterns of subsequent adjustments were significantly different between discretionary and nondiscretionary disposals at the 0.01 level, with discretionary disposals being more likely to lead to additional loss accruals. ${ }^{8}$

Table 1, Panel A provides a breakdown of sample firms by SIC classification, separated by the type of disclosure. While firms were represented within each of the one-digit SIC codes, approximately 40 percent of both the discretionary and nondiscretionary samples came from the industrial codes 3000 to 3999 . The relative frequency across the SIC codes is similar for both samples. Panel B of Table 1 summarizes the distribution of our sample firms by year, partitioned by the type of disclosure (discretionary versus nondiscretionary). As with industry membership, the data suggest that the type of disposal is not associated with the year of recognition. Finally, Panel C of Table 1 reports significant differences in the quarterly announcement pattern of the two sets of firms. ${ }^{9}$ Seventy-seven percent of the discretionary discontinuances were disclosed in the firms' fourth quarters as compared to only 50 percent of the nondiscretionary disposals. This difference in proportions is significant at the 0.01 level.

\subsection{TESTS OF MOTIVATION TO ANNOUNCE THE DECISION TO ADOPT A PLAN OF DISPOSAL}

\subsection{Motivation For Early Adoption Of A Plan Of Disposal}

While APB 30 and SFAS 144 permit a firm to choose whether to report a segment disposal at the time disposal is complete or at some earlier plan adoption date, neither provide much guidance on when plan adoption should occur. As such, segment disposals provide a unique opportunity to examine announcement timing that may be chosen to maximize the benefit to the firm. This context is unique for a number of reasons. First, segment disposals can result in either gains or losses. ${ }^{10}$ Second, details of the operating performance by a poorly performing unit are reclassified from "above the line" income from continuing operations at the time of the announcement. Third, any benefits from reclassification can be accelerated by announcing a plan prior to the actual disposal date. Finally, the plan adoption announcement potentially puts the unit in play, perhaps generating greater external interest in the unit.

Some motivations for both the choice and its timing might be inferred from the literature on discretionary announcements of asset restructurings. The prior research (e.g., Elliott and Shaw 1988) suggests that firms engage in discretionary restructurings when firms are at historically weak performance levels, and that the announcements tend to be clustered in the fourth quarter of firms' fiscal years. Since discretionary segment disposals possess similar discretionary aspects (i.e., firms have not consummated the disposal of the segment and thus have significant leeway on when to disclose their plans for disposition), we expect that firms reporting discretionary discontinuances to exhibit similar characteristics. However, the characteristics of segment disposals described in the previous paragraph suggest two additional benefits arising from early or discretionary recognition. First, a firm can benefit from early adoption of a plan of disposal because, upon plan adoption, the results of operations of a poorly performing unit are reclassified from the results of operations of the presumably better performing continuing portion of the firm. Second, if a firm adopts a disposal plan because of poor segment earnings, it is likely beneficial to announce the plan as early as possible to hasten the segregation of the effects of the segment from continuing operations. This motivates our two primary research expectations with respect to the timing of plan adoption. First, because segment results are reclassified, we expect to observe a positive association between weaker segment performance and the likelihood of discretionary segment disposals. Second, for the same reclassification reason, firms that have both weaker continuing operating performance and financial condition when compared to their nondiscretionary counterparts should also elect 
discretionary disposal treatment.

\subsection{Tests Of Election To Report The Transaction Prior To The Disposal Date}

\subsubsection{Sample Firm Profiles}

We examine our predictions first by profiling the operating results of the two sets of firms and their discontinued segments. Table 2 reports descriptive statistics and our comparisons of these profiles. In Panel A, we document the magnitude and frequencies of initial provisions and subsequent adjustments, and the details of segment operating performance. Consistent with our expectations, we find 87 percent of firms reporting discretionary disposals initially disclosed expected losses compared to only 37 percent of the firms disclosing nondiscretionary disposals. ${ }^{11}$ The median loss of \$(4.311) million or 2.4 percent of total assets was significantly more negative than the amounts associated with nondiscretionary disclosures. As previously noted and consistent with our expectations, the discretionary charges were also more likely to be accompanied by more negative subsequent adjustments. We find that segments associated with discretionary disposals sustained significantly weaker long-term operating performance when compared to the performance of those segments associated with nondiscretionary disposals. These results suggest that firms electing discretionary disposals may have stronger motivations to reclassify the relatively poorer performing segments out of continuing earnings prior to disposal.

With respect to firm profiles, Panel B of Table 2 documents no significant differences in firm size based on either total assets or total sales over our five-year event window centered on the announcement year. However, consistent with our expectations, firms reporting discretionary disposals had significantly lower levels of continuing earnings in years 0 and +1 than firms reporting nondiscretionary disposals, and were significantly more leveraged in years $0,+1$, and +2 . Further, firms recording discretionary disposals were somewhat more likely to report additional above-the-line restructuring charges. However, there was no difference across the two samples in the likelihood of experiencing a change in top management in either year 0 or year -1 .

\subsubsection{Joint Tests}

Next, we examine the joint roles of segment and firm characteristics on plan adoption timing by developing a cross-sectional probit model of the election decision. We estimate the following model:

$\left.\left.\operatorname{Pr}\left[D I S C R_{\mathrm{i}}=1\right]=\beta_{0}+\beta_{1} P R O V_{\mathrm{i}}+\beta_{2} S E G_{\mathrm{i}}+\beta_{3}\right) S E G_{\mathrm{i}}+\beta_{4} Q T R_{\mathrm{i}}+\beta_{5} M G M T_{\mathrm{i}}+\beta_{6} R E S T R_{\mathrm{i}}+\beta_{7} I F C O_{\mathrm{i}}+\beta_{8}\right) I F C O_{\mathrm{i}}$

$$
+\beta_{9} L E V_{\mathrm{i}}+e_{\mathrm{i}}
$$

where $D I S C R_{\mathrm{i}}=1$ if firm $i$ reported a discretionary segment disposal, 0 otherwise; $P R O V_{\mathrm{i}}=$ the initial provision on disposal reported by firm $i$ (where initial losses carry negative signs), deflated by firm total assets; $S E G_{\mathrm{i}}=$ year 0 earnings of the discontinued segment for firm $i$, deflated by firm total assets; $) S E G_{\mathrm{i}}=$ change in year 0 segment earnings from year -1 for firm $i$, deflated by firm total assets; $Q T R_{\mathrm{i}}=1$ if firm $i$ recognized the discontinuance of its segment in the fourth quarter of firm $i$ 's fiscal year, 0 otherwise; $M G M T_{\mathrm{i}}=1$ if firm $i$ experienced a change in top management in either fiscal year 0 or fiscal year $-1,0$ otherwise; $R E S T R_{\mathrm{i}}=1$ if firm $i$ also reported an "above-theline" restructuring charge in year 0,0 otherwise; $I F C O_{\mathrm{i}}=$ year 0 continuing return on assets for firm $i$; )IFCO change in year 0 continuing return on assets from year -1 for firm $i ; L E V_{\mathrm{i}}=$ ratio of total liabilities to total assets in year 0 for firm $i ; \beta_{\mathrm{i}}$ are parameters to be estimated; and $e_{\mathrm{i}}$ is a firm-specific error term. ${ }^{12}$ In order to control for potential differences in strategic motivations between firms within industries as well as industry differences in return on assets and financial condition, we incorporate industry-adjusted firm earnings and leverage measures into our regression model. ${ }^{13}$

Our expectations for the explanatory factors follow from our research hypotheses. With respect to segment characteristics, we expect that firms are more likely to elect discretionary disposals for segments requiring larger write-downs and larger loss accruals for disposal-period operating performance, and for segments with relatively lower earnings levels and more negative earnings changes. Such actions would lead to the reclassification of losses 
out of continuing earnings as early as possible, so that continuing earnings are improved as a result. This suggests negative signs on PROV, SEG, and )SEG. With respect to firm characteristics, we expect that firms engaging in other restructuring actions and firms with recent changes in top management are more likely to adopt discretionary treatment for their segment disposals. This would be consistent with a "clearing of the decks" associated with corporate restructurings and a desire to more closely reflect "core" earnings. This leads us to anticipate positive signs on MGMT and RESTR. Consistent with the reclassification of poor segment operating results tending to help firms with poor continuing earnings, we expect that firms with lower levels of continuing earnings and larger declines in continuing earnings to be more likely to elect discretionary treatment for their segment disposals. This implies negative signs on IFCO and )IFCO. We also expect firms in poorer financial condition, as proxied by the industryadjusted ratio of total liabilities to total assets, will adopt discretionary treatment of their segment disposals, leading to an expected positive sign on $L E V$. Finally, because of the results in Panel C of Table 1, we include as a control the indicator variable $Q T R$.

The estimates associated with our model are reported in Table 3. Consistent with most of our expectations and with the results in Panel A of Table 2, we find that firms discontinuing segments with sharper declines in earnings and requiring larger initial losses on disposal are more likely to adopt discretionary disposal treatment. With respect to firm characteristics, less profitable firms, firms with sharper declines in continuing earnings, and firms in poorer financial condition are also more likely to adopt discretionary disposals. This suggests that firms reporting discretionary write-offs may have incentives to manage the timing of the adoption and disclosure of the plan of disposal.

\subsection{DETERMINANTS OF ADJUSTMENTS TO INITIAL PROVISION FOR DISPOSAL}

We next examine the issue of why firms make errors in their estimates of initial provisions. This question is relevant since the choice of when to announce the segment disposal determines the degree to which accounting estimates make up any initial provision included in the announcement. Of the 143 firms reporting a discretionary disposal, 95 (or 66 percent) reported subsequent adjustments to their initial provisions. Not surprisingly, nondiscretionary disposals are less likely to lead to adjustment (since disposal activities are essentially complete when plan adoption occurs); only 44 (or 35 percent) of the 126 firms disclosing a nondiscretionary disposal reported subsequent adjustments to initial provisions.

We expect that uncertainty and errors in estimating disposal values and disposal period segment earnings play a role in determining the occurrence and magnitude of subsequent adjustments. However, if early announcement of an intent to dispose is consistent with firms' attempts to manage the release of unfavorable news, then subsequent adjustments may also reflect firms' efforts to strategically manage the magnitude of the unfavorable news by manipulating the initial provision. Therefore, we model the associations between subsequent adjustments and segment-level and firm-level attributes. We expect that segment-level attributes will capture the effects of uncertainty and errors of measurement in the choice of initial provision, while firm-level attributes will proxy for the influence of managerial and strategic incentives on that choice. Since discretionary and nondiscretionary disposals differ in the degree to which managers have discretion to estimate initial provisions, we separately estimate cross-sectional models of the associations between the explanatory variables and the observed subsequent adjustments for the two groups.

We use as our dependent variable ADJUST, the cumulative subsequent adjustment to an initial provision reported by firm $i$ in years +1 and +2 following the disposal, deflated by year 0 firm $i$ total assets. ADJUST carries a negative (positive) sign if the cumulative subsequent adjustment was an overall loss (overall gain). We limit the window for adjustment measurement to the two years following the discontinuance because adjustments occurring after this period are likely to reflect contemporaneous events rather than information reasonably estimable at the time of discontinuance. ${ }^{14}$

\subsection{Discretionary Disposals} follows:

The cross-sectional model we use to explain subsequent adjustments in discretionary disposals is specified as 


$$
\begin{aligned}
A D J U S T_{\mathrm{i}}= & \left.\beta_{0}+\beta_{1} P R O V_{\mathrm{i}}+\beta_{2} S E G_{\mathrm{i}}+\beta_{3}\right) S E G_{\mathrm{i}}+\beta_{4} P E R_{\mathrm{i}}+\beta_{5} P E R_{\mathrm{i}} x S E G_{\mathrm{i}}+\beta_{6} M G M T_{\mathrm{i}}+\beta_{7} I F C O_{\mathrm{i}}+\beta_{8} D E C L_{\mathrm{i}}+ \\
& \beta_{9} I M P R_{\mathrm{i}}+\beta_{10} F U T U R E_{\mathrm{i}}+\beta_{12} L E V_{\mathrm{i}}+\beta_{13} D E B T_{\mathrm{i}}+\beta_{14} L E V_{\mathrm{i}} x D E B T_{\mathrm{i}}+e_{\mathrm{i}}
\end{aligned}
$$

Each of the variables in this model is defined and discussed in the following sections; the $\beta_{\mathrm{i}}$ represent parameters to be estimated and $e_{\mathrm{i}}$ is a firm-specific error term.

\subsection{Description Of Variables In The Discretionary Disposal Regression}

\subsubsection{Variables Representing Potential Errors In Measuring Disposal Values And Future Segment Performance}

Discretionary disposals require firms to estimate gains or losses on revaluation of segment assets and to estimate segment earnings during the disposal period. Revaluation may be difficult if firms have few bases for comparison in estimating the market values of segment assets in use. Estimating segment operating performance may be difficult if it is unclear how long the disposal will take. We develop a set of variables to measure the extent to which this uncertainty leads to systematic measurement error in the estimates of the initial provisions. With the first five variables in the model, we test if subsequent adjustments are related to (1) the magnitude of the initial provision, (2) a systematic miss-measurement of the expected future performance of the disposed segment, and (3) the length of the disposal period.

\subsubsection{Magnitude Of The Initial Loss Provision}

The adequacy of the initial provision should affect the level of subsequent adjustments needed. In other words, smaller initial provisions will more likely be inadequate and lead to overstated asset values, requiring later recognition of additional losses. We include the variable $P R O V$, measured as the magnitude of the initial provision, deflated by firm assets, to address this issue. Since initial losses are negatively signed, we predict a negative association between the magnitude of the initial provision and the observed subsequent adjustment.

\subsubsection{Segment Earnings Performance}

We expect that more negative segment earnings levels may suggest a greater likelihood that disposal period segment earnings will be less than forecast. This suggests a positive association between the level of segment earnings and subsequent adjustments. With respect to the changes in segment earnings, we suggest that more extreme declines in segment earnings are likely to be transitory. This suggests that disposal period losses may be less than expected, and would imply a negative association between segment earnings changes and subsequent adjustments. We define the variable $S E G$ as the level of pre-measurement-date segment earnings in the write-off year (year 0), deflated by firm assets, and we define the variable )SEG as the change in the level of segment earnings from year -1 to year 0 , deflated by firm assets.

\subsubsection{Extended Disposal Period}

APB 30 implies that, if management is undertaking an active plan for the disposal of a segment, then disposal of the segment should be completed within one year of the measurement date. If a segment is not disposed of in one year or less, management may have been overly optimistic about its ability to dispose of the segment. Subsequent review by managers and/or auditors may lead to additional write-downs of those assets, suggesting a negative association between extended disposal periods and subsequent adjustments (Kinney and Martin 1994). ${ }^{15}$ We define the variable $P E R$ to take on the value of 1 if the time required to effect disposal exceeded one year, zero otherwise.

The effect of an extended disposal period on subsequent adjustments is, however, likely to depend on the earnings of the segment during the disposal period and/or any actions by the firm to improve the operating performance or reduce the losses of the segment prior to sale. Absent any actions by the firm to intervene in the operations of the segment, an unprofitable segment operated for a period exceeding a year is likely to result in 
additional operating loss accruals, while a profitable segment could lead to subsequent earnings in excess of expectations upon completion of disposal. On the other hand, if segment operating losses during the disposal process are subsequently reversed by significant layoffs and other management actions, an extended disposal period could result in estimated losses being less than expected. To capture any interaction between segment operating performance and extended disposal periods, we incorporate in our model the interaction between an extended disposal period and the segment earnings level [PER $x$ SEG]. The first explanation provided above would suggest a positive association between this interaction term and subsequent adjustments, while the second explanation would suggest a negative association.

\subsubsection{Variables Representing Strategic Incentives To Manage Disclosures}

We expect the remaining variables in the model to proxy for firms' motivations to manage earnings and balance sheet positions through their choice of initial provision. Three factors are considered here: recent change in top management, current and future earnings performance of the continuing unit, and restrictions included in debt covenants.

\subsubsection{Management Change}

A number of prior studies examining firm write-off behavior have found that management change is strongly associated with a higher frequency of write-offs (e.g., Elliott and Shaw 1988; Francis, Hanna and Vincent 1996; Pourciau 1993). However, if new management chooses to "purge the books" and take excessive write-offs when recognizing the discontinuance, we should observe positive (i.e., gain) adjustments in the years after the plan adoption. Similar to other research (e.g., Francis et al. 1996), we include an indicator variable, MGMT, which takes on a value of 1 if there was a change in top management (chairman of the board, chief executive officer, or president) in either year 0 or year -1. If management change is associated with excessive write-offs, a positive association between the incidence of management changes and subsequent adjustments would be predicted.

\subsubsection{Current-Period And Future-Period Continuing Earnings Performance}

Previous research has suggested that current-period earnings performance is associated with write-off behavior (e.g., Elliott and Shaw 1988; Moerhle 2002; Francis et al. 1996; Zucca and Campbell 1992). Each suggests that write-offs are more likely to occur in firms that have poor current operating performance. Other research has found that managers' actions are influenced both by earnings levels and by earnings changes (e.g., Burgstahler and Dichev 1997). ${ }^{16}$

Similar to Francis et al. (1996), we define separate variables to measure when current-period earnings are better or worse relative to the prior year. We define earnings performance as unexpected return on assets $(U R O A)$, measured as year 0 income from continuing operations minus year -1 income from continuing operations, divided by firm assets. Our proxy for declining (improving) performance is $D E C L=U R O A$ if $U R O A<0,0$ otherwise $(I M P R=$ $U R O A$ if $U R O A>0,0$ otherwise). ${ }^{17}$ Prior findings of a tendency of firms to recognize nonrecurring items when earning performance is extreme may also suggest a tendency to take excess write-offs or loss accruals under similar conditions. We therefore predict a negative (positive) association between DECL (IMPR) and subsequent adjustments.

We also include the current-period level of continuing earnings (IFCO), measured as income from continuing operations in the disposal year, deflated by firm assets. If more profitable firms choose to fully recognize any losses in the year of the disposal and less profitable firms choose to minimize any hit to current-period earnings (which could lead to additional loss accruals in the subsequent year), we would expect to observe a positive association between IFCO and subsequent adjustments.

Given that discretionary disposals have the potential to affect net income in two or more periods, firms may also choose initial provisions based on expectations of future earnings performance or in an attempt to shift earnings between periods (DeFond and Park 1997). Assuming that future continuing earnings realizations are a reasonable 
proxy for ex ante expectations about those earnings, we incorporate the variable, FUTURE, defined as the change in continuing earnings from year 0 to year +1 , deflated by firm assets. If managers "purged the books" in year 0 and, perhaps, even accelerated expected continuing expenses from year +1 into the year 0 initial provision, this would suggest an association between the change in earnings from year 0 to year +1 and subsequent adjustments. Specifically, to the extent that (1) these excessive accruals of future continuing expenses were incorporated into the initial provision and (2) these excess "reserves" were subsequently reversed, subsequent adjustments should be positively associated with year +1 earnings changes.

\subsubsection{Financial Leverage Of The Firm}

The "debt-equity" hypothesis (Watts and Zimmerman 1986, 1990) suggests that, as firms' leverage ratios increase, accounting-based debt covenants become more restrictive and the probability of violation of these covenants increases. Since the costs of violation may be high, shifting earnings into the current period through understatement of the initial loss provision might reduce the likelihood of technical default. This would suggest a negative association between the degree of financial leverage and subsequent adjustments. We use as our proxy for firm leverage the ratio of firm total liabilities to firm total assets $(L E V)$ in the year of the write-off.

In contrast, for firms already in poor health and already in violation of their debt covenants, the incremental cost of reporting a larger loss is likely to be small and the incentive to shift earnings into the future by overstating losses may be relatively strong. We model this combination of circumstances by including a variable, $D E B T$, indicating whether a firm disclosed a debt covenant violation in the year of the write-off $(D E B T=1$ if firm $i$ disclosed a covenant violation, 0 otherwise), and the interaction between a firm's leverage ratios $(L E V)$ and the occurrence of a debt covenant violation in the year of the write-off (DEBT). We predict positive signs on both $D E B T$ and $L E V x$ $D E B T$.

\subsection{Results Of The Regression}

The first panel of estimates in Table 4 presents the regression results for discretionary disposals. As predicted, we find significant associations between subsequent adjustments and both segment-level variables and firm-level variables. These associations jointly explain over 60 percent of the cross-sectional variability in subsequent adjustments. Consistent with the presence of systematic miss-measurement of the segments' performance during the disposal period, we find that the amount of the subsequent adjustment is more positive (less negative) in conjunction with more negative initial provisions, better segment earnings, and shorter disposal periods. We find a positive association between adjustments and the interaction of extended disposal periods and segment performance, suggesting aggressive actions were undertaken by firms to reduce segment operating losses during the extended disposal periods.

We also find evidence of firm characteristics influencing the size of the adjustment. Subsequent adjustments are more positive (less negative) in conjunction with top management changes, higher continuing earnings levels, more extreme declines and improvements in continuing earnings relative to the prior year, and more positive expected future continuing earnings. We find little evidence of an association between subsequent adjustments and debt levels or poor financial condition.

\subsection{Nondiscretionary Disposals}

In contrast, for nondiscretionary disposals, there is little reason a priori to expect adjustments to the initial provisions due to miss-measurement of the segments' future performance or due to any strategic incentives to manipulate reported provisions. These transactions are essentially complete; therefore, future segment performance may be irrelevant (since segments are no longer owned by the firms), and any reported gains or losses on disposal are primarily realizations rather than estimates (suggesting managers' ability to influence the measurement of the amount may be constrained). This suggests subsequent adjustments should be attributable to little more than random errors, which would be reflected in the unexplained variability in the data. To determine if adjustments for these transactions arise as a result of the same forces hypothesized in the previous section, we use a similar model to estimate these 
associations:

$$
\begin{aligned}
\text { ADJUST }_{\mathrm{i}}= & \left.\beta_{0}+\beta_{1} \text { PROV }_{\mathrm{i}}+\beta_{2} S E G_{\mathrm{i}}+\beta_{3}\right) S E G \mathrm{i}+\beta_{4} U N C E R T_{\mathrm{i}}+\beta_{5} U N C E R T_{\mathrm{i}} x S E G_{\mathrm{i}}+\beta_{6} M G M T_{\mathrm{i}}+\beta_{7} I_{F C O} O_{\mathrm{i}} \\
& +\beta_{8} D E C L_{\mathrm{i}}+\beta_{9} I M P R_{\mathrm{i}}+\beta_{10} \text { FUTURE }_{\mathrm{i}}+\beta_{12} L E V_{\mathrm{i}}+\beta_{13} D E B T_{\mathrm{i}}+\beta_{14} L E V_{\mathrm{i}} x D E B T_{\mathrm{i}}+e_{\mathrm{i}} .
\end{aligned}
$$

The definitions of the common variables are given in Section 5.2.

Note that the only difference between this model and that for discretionary disposals is in the removal of the two terms involving PER, and the inclusion of the two terms involving UNCERT. While some firms involved in nondiscretionary disposals may have definitive contracts with buyers for the disposal of their segment, for various reasons (e.g., regulatory and IRS approvals), the two parties may not have finalized all aspects of the disposal or closed on the deal. To capture this uncertainty and to distinguish between transactions that are unambiguously completed as of the balance sheet date and those for which some uncertainty remains, the indicator variable UNCERT is included. UNCERT takes on the value of 1 if the disposal of the segment was still subject to some contingencies as of the balance sheet date (as disclosed in the footnotes), and zero otherwise. Since any remaining contingencies may relate to future segment performance and may delay the date of final closing, we also include the interaction between UNCERT and SEG. We make no prediction as to the sign on UNCERT; however, for reasons outlined in Section 5.2 and to the extent that the uncertainty leads to a delay in the final close of the transaction beyond expectations, we expect a positive sign on the interaction term. ${ }^{18}$

The second panel of estimates in Table 4 presents the regression results for nondiscretionary disposals. The overall model is significant at the 0.03 level, but this result is largely driven by the segment-level variables. Consistent with our expectations, only UNCERT and UNCERT $x$ SEG of the segment-level variables are significant at conventional levels. This suggests that uncertainty about contingencies leading to measurement error is the primary factor explaining subsequent adjustments. While we made no prediction on the sign on UNCERT, the positive sign suggests that, unconditional on the performance of the discontinued segment, remaining uncertainties are resolved in favor of the parent. This result could also suggest that firms recorded excessive loss accruals to provide for these uncertainties. Of the firm-level variables, only $L E V$ is significant at conventional levels; however, the firm-level variables as a group are not significant $(p=0.14)$, suggesting managers' ability to manage the choice of initial provisions and/or adjustments is constrained by the completeness of the transaction.

\subsection{SENSITIVITY TESTS}

Several sensitivity tests were generated focusing on both the discretionary and nondiscretionary disposal results. We re-examined the data to determine if the results differed with the exclusion of the "no adjustment" firms. Subsequent analyses excluding these firms yield results that are qualitatively similar to those reported in Table 4 . We also changed the specification of the dependent variable (ADJUST) to deflate the subsequent adjustment by the absolute value of the initial provision. Results were similar to those reported in Table 4 except that $D E C L$ and $I F C O$ were not significant at conventional levels. We computed condition numbers for the two matrices of explanatory variables representing the two models. Neither condition number exceeded 10, which is well below the generally accepted level of 20 (Greene 1993). This suggests that multicollinearity was not a factor in our results.

In order to determine whether our results pertaining to discretionary disposals are dependent on industry effects or on time period-specific macroeconomic factors, we re-estimated our model first by including indicator variables for industry membership (at the single-digit SIC code level), and then by including indicator variables for the year of write-off. In both cases, a number of these indicator variables are significantly associated with subsequent adjustments; however, our basic inferences for discretionary disposals regarding firm-level and segment-level variables are, for the most part, generally consistent with those reported in Table $4 .{ }^{19}$

We also re-estimated the model of discretionary write-off adjustments after excluding influential observations and observations with standardized residuals in excess of 2.0 (a total of 19 observations). Results generally consistent with those reported in Table 4 were obtained, although, for the firm-level attributes, both $D E C L$ 
and IMPR were not significant at conventional levels, IFCO was significantly negative, and both $L E V x D E B T$ and $L E V$ were highly significant in the predicted directions

Similar sensitivity analyses involving nondiscretionary disposals also yielded results that were very similar to those reported in Table 4. Specifically, the addition of the year and industry indicator variables led to significant improvements in the models, but there were no significant changes in the inferences reported in the previous section. An analysis involving nondiscretionary disposals after exclusion of influential observations and observations with large standardized residuals yielded a model that overall was not significant at conventional levels.

To determine if firms were simultaneously using discretionary accruals to manage earnings in directions consistent with the observed adjustments, we estimated both total accruals (Healy 1985) and discretionary accruals (Dechow, Sloan and Sweeney 1995) for those firms with available data. In general, we find little evidence that is consistent with firms using discretionary accruals in order to manage earnings in a way that is also consistent with the earnings effects associated with observed subsequent adjustments. Further, a comparison of firms reporting discretionary and nondiscretionary disposals reveals little evidence consistent with differences in accrual behavior between these two groups. For both types of disposals, these results suggest that the observed subsequent adjustments do not arise simply because sample firms differ on the basis of their willingness or ability to choose discretionary accruals.

\subsection{DISCUSSION AND IMPLICATIONS}

This paper has examined two issues with respect to the recognition of segment disposals (or discontinued operations). We first examine whether the timing of the announcement of segment disposals can be explained by segment-level and firm-level attributes. We find that firms elect discretionary disposals when discontinuance leads to relatively more negative initial provisions and when discontinued segments experience sharp declines in earnings. With respect to the continuing portions of the firms, we find that firms reporting discretionary disposals are less profitable and suffer more extreme declines in continuing earnings, and they are more highly leveraged than firms that defer the recognition until completion of disposal. Consistent with Rapaciolli and Schiff (1991), this suggests that these firms may be strategically timing their announcements of the transaction to cast the disposal in the best light.

We next ask whether systematic measurement errors or management incentives can explain the subsequent adjustment phenomenon. For discretionary disposals, the observed associations between subsequent adjustments and segment-level variables suggest that uncertainty and measurement error may play a significant role in explaining the closeness of initial provisions. The observed associations between firm-level variables and subsequent adjustments also suggest that firms' loss measurements are influenced by managerial incentives to set initial provisions. For nondiscretionary transactions, adjustments appear to be associated with uncertainty-induced measurement error of segment operating performance, but that systematic effect appears relatively small. Management incentives have little impact in explaining adjustments in nondiscretionary disposals.

Inadequate disclosure and a lack of adequate controls for the various measurement issues inherent in estimating restructuring charges have hindered the examination of the earnings management implications of these charges. We have identified a restructuring context where both of these problems are mitigated by more detailed disclosures. Specifically, we can observe both the initial provisions arising from the disposal and any adjustments to those provisions, and we can observe the operating results of the assets being disposed of. Consistent with standard setters' concerns, we find evidence consistent with manipulation of initial provisions when managers have (1) discretion to estimate and disclose those provisions, and (2) incentives to bias the measurement of the provision. But we find little or no evidence consistent with provision manipulation when managers' discretion to estimate the accruals is constrained due to the completeness of the transaction. Since this evidence is observed only in discretionary discontinued operations disclosures which are reported as "below the line" restructuring charges, the likelihood that strategic incentives play a role in managers" choice of "above-the-line" restructuring charge magnitude is probably significantly higher. 
The authors gratefully acknowledge comments on earlier versions of this paper from Barry Lewis, Tom Buchman, 4 Steve Henning, Don Waldman, Austin Reitenga, Steve Buchheit, Katherine Schipper, Bob Lipe, Terry Warfield, In-Mu Haw, Linda Smith Bamber, and Jennifer Gaver. Valuable suggestions were also provided by workshop participants at the University of Colorado at Boulder, Colorado State University, University of Wisconsin-Madison, Rice University, Texas Christian University, the University of Houston, and at the 1998 Summer Accounting Research Conference at the University of Texas at Austin.

\section{REFERENCES}

1. American Institute of Certified Public Accountants. 1973. APB Opinion No. 30, Reporting the Results of Operations. New York, NY: AICPA.

2. Bartov, E., F. W. Lindahl, and W. E. Ricks. 1998. Stock price behavior around announcements of writeoffs. Review of Accounting Studies 3(4): 327-346.

3. Burgstahler, D. and I. Dichev. 1997. Earnings management to avoid earnings decreases and losses. Journal of Accounting and Economics 24: 99-126.

4. Dechow, P. M., M. R. Huson, and R. G. Sloan. 1994. The effect of restructuring charges on executives' cash compensation. The Accounting Review 69 (January): 138-156.

5. Dechow, P. M., R. G. Sloan, and A. P. Sweeney. 1995. Detecting earnings management. The Accounting Review 70 (April): 193-225.

6. Defeo, V. J., R. A. Lambert, and D. F. Larcker. 1989. Executive compensation effects of equity-for-debt swaps. The Accounting Review 64 (April): 201-227.

7. DeFond, M. L. and C. W. Park. 1997. Smoothing income in anticipation of future earnings. Journal of Accounting and Economics 23: 115-139.

8. Elliott, J. A. and D. Hanna. 1996. Repeated accounting write-offs and the information content of earnings. Journal of Accounting Research 34 (Supplement): 135-155.

9. Elliott, J. A. and W. H. Shaw. 1988. Write-offs as accounting procedures to manage perceptions. Journal of Accounting Research 26 (Supplement): 91-119.

10. Francis, J., D. Hanna, and L. Vincent. 1996. Causes and effects of discretionary asset writeoffs. Journal of Accounting Research 34 (Supplement): 117-134.

11. Financial Accounting Standards Board. 1975. Statement of Financial Accounting Standards No. 5, Accounting for Contingencies. Norwalk, Connecticut: FASB.

12. Financial Accounting Standards Board. 2001. Statement of Financial Accounting Standards No. 144, Accounting for the Impairment or Disposal of Long-Lived Assets. Norwalk, Connecticut: FASB.

13. Gaver, J. J. and K. M. Gaver. 1998. The relation between nonrecurring accounting transactions and CEO cash compensation. The Accounting Review 73 (April): 235-253.

14. Gaver, J. J., K. M. Gaver, and J. R. Austin. 1995. Additional evidence on bonus plans and income management. Journal of Accounting and Economics 19 (February): 3-28.

15. Greene, W. H. 1993. Econometric Analysis. $2^{\text {nd }}$ edition. New York, NY: Macmillan.

16. Healy, P. M. 1985. The effect of bonus schemes on accounting decisions. Journal of Accounting and Economics 7: 85-107.

17. Healy, P. M., S. Kang, and K. G. Palepu. 1987. The effects of accounting procedure changes on CEOs' cash salary and bonus compensation. Journal of Accounting and Economics 9 (January): 7-34.

18. Kinney, W. R., Jr. and R. D. Martin. 1994. Does auditing reduce bias in financial reporting? A review of audit-related adjustment studies. Auditing: A Journal of Practice \& Theory 13 (Spring): 149-156.

19. Levitt, A. 1998. The numbers game. Remarks at the NYU Center for Law and Business, New York, NY (September).

20. Loh, A., T. T. Hoe, and T. Wilkins. 2001. The role of the discretionary accruals and classification decisions in the management of earnings. Unpublished working paper

21. Moerhle, S. R. 2002. Do firms use restructuring charge reversals to meet earnings targets? The Accounting Review 77 (April): 397-413.

22. Pourciau, S. 1993. Earnings management and nonroutine executive changes. Journal of Accounting and Economics 16: 317-336. 
23. Rapaciolli, D. and A. Schiff. 1991. Reporting sales of segments under APB Opinion No.30. Accounting Horizons (December): 53-59.

24. Watts, R. L. and J. L. Zimmerman. 1986. Positive Accounting Theory. Englewood Cliffs, NJ: Prentice-Hall. 25. Watts, R. L. and J. L. Zimmerman. 1990. Positive accounting theory: A ten-year perspective. The Accounting Review 65 (January): 131-156.

26. White, H. 1980. A heteroskedasticity-consistent covariance matrix estimator and a direct test for heteroskedasticity. Econometrica (May): 817-838.

27. Wilson, G. P. 1996. Discussion: Write-offs: Manipulation or impairment? Journal of Accounting Research 34(Supplement): 171-177.

28. Zucca, L. J. and D. R. Campbell. 1992. A closer look at discretionary writedowns of impaired assets. Accounting Horizons (September): 30-41.

\section{ENDNOTES}

| 1. Adjustments can represent either additional loss accruals or reversals of accruals. Moehrle (2002) identified a total of only 114 firms announcing reversals of restructuring charges over the period from 1990 to 1999, and of these was able to use only 83 or 121 firm-quarters in his analysis (depending on modeling approach). Elliott and Shaw identified only one out of 240 firms disclosing a reversal. On the other hand, Elliott and Hanna (1996) document that 27 percent of firms taking write-offs in one year also recognize another write-off in the subsequent year, although they do not report whether the subsequent write-off represented an adjustment to the initial write-off.

| 2. APB 30 has been superceded by SFAS 144, Accounting for the Impairment or Disposal of Long-Lived Assets, which was issued in August 2001 and is effective for financial statements issued for fiscal years beginning after December 15, 2001. The revisions to the accounting standards for segment disposals are discussed in accompanying footnotes.

| 3. In contrast, SFAS 144 now requires firms to exclude from the estimates of the initial provision any estimated segment operating performance during the anticipated disposal period, and instead disclose (as part of income from discontinued operations) the disposal period operating results when realized. Discussion underlying the decision focused on the notion that any estimated operating losses during the period did not meet the definition of a liability.

SFAS 144 continues these requirements.

5. In a number of cases, a firm discontinued more than one segment in a given accounting year. Such firms were included in the discretionary sample if aggregated earnings for the portfolio of segments was disclosed and if the transaction was not essentially completed. The transaction was considered essentially complete if disposal of a majority of the portfolio was accomplished by the time the financial statements are issued.

| 6. Examples of inadequate or insufficient disclosure included segment earnings not separately disclosed, commingled segment earnings for successive write-offs, subsequent adjustments that were not associated with a particular write-off, information on other model variables not available.

| 7. Most firms recorded such adjustments in the accounting period subsequent to the write-off period. However, a few of the sampled firms recorded multiple adjustments; i.e., adjustments were made in both of the periods following the write-off. In such cases, the net amount of the two adjustments was the amount recorded. Each of these firms recorded overall additions to the initial write-off provision, while none recorded overall reversals of the initial provisions.

| 8. This result is not necessarily surprising. To the extent that managers are only able estimate a range of possible loss provisions and are unable to choose a loss in that range, then SFAS 5 (FASB 1975) requires managers to accrue the smaller of the two amounts and to disclose the greater of the two amounts. If managers systematically accrue a lower limit, then adjustments are likely to be biased downward. Interestingly, however, no firm in our sample disclosed upper and lower limits on the range.

19. In a number of cases, even though the disposal was recognized in the fourth quarter according to a firm's annual report, the actual announcement occurred after the close of the firm's fiscal year, so that the announcement actually occurred in the first quarter of the following year. This was observed for 21 of the 143 discretionary disposals and 15 of the 126 nondiscretionary disposals.

10. Rapaciolli and Schiff (1991) document a tendency of firms to disclose disposal losses below income from continuing operations, while disposal gains tend to be reported as part of continuing operations. Loh et al. (2001) report similar results. However, as far as we could tell, neither paper makes a distinction between what we characterize as discretionary and nondiscretionary segment disposals.

11. Consistent with APB 30 constraining the ability of firms to recognize gains on disposal prior to realization, none of the discretionary adopters recognized an initial estimated gain on disposal.

| 12. Diagnostics suggested the use of heteroskedastic probit analysis. Qualitatively similar parameter estimates were obtained and similar statistical inferences were made when using standard probit analysis with robust standard errors. 
13. Somewhat weaker results on the measures of continuing performance are obtained when unadjusted earnings and leverage measures are used in the regression.

14. Only a very few firms required disposal periods in excess of two years and these were primarily in the insurance and real estate industries.

15. It may be that the initial loss estimate may be subject to less scrutiny by the firm's external auditors because of the below-the-line treatment of the write-off, and because management's representations of the earnings effect of the writeoff may have seemed reasonable at the time. Additional information that becomes available during the disposal period may lead to doubts about the realizability of the restated asset values.

16. Since segment disposals are presented below income from continuing operations, managers' manipulation of the initial provision would have direct effects on net income rather than on continuing earnings. If continuing earnings are the basis for bonus calculations, managers would have little incentive to manipulate initial provisions, unless the manipulation could somehow affect continuing earnings. However, Gaver, Gaver, and Austin (1995) document that results of discontinued operations are rarely excluded from the earnings definition used for bonus determination. There is also evidence that nonrecurring items flow through the compensation function (e.g., Gaver and Gaver 1998; Defeo, Lambert, and Larcker 1989; Healy, Kang, and Palepu 1987), while other research suggests that executive compensation is shielded from nonrecurring charges (Dechow, Huson and Sloan 1995).

| 17. We also measured unexpectedly good earnings in a manner consistent with Francis et al. (1996). Specifically, unexpectedly good performance is defined as positive values of UROA in excess of the amount of the initial provision. We obtained results that were virtually identical to those reported in Table 4.

18. Unlike the discretionary disposals, we would not expect the firm to attempt to impose operating efficiencies on a segment for which a contract for sale exists. How the segment is operating up to the measurement date is therefore likely to continue during any delay in closing that might arise from the existing uncertainty. Therefore, we believe the positive association can be predicted unambiguously.

19. Specifically, when the model included industry indicators, $L E V, D E B T$, and $L E V \times D E B T$ were not significant at conventional levels. When the model included year indicators, $L E V, D E B T$, and $L E V \times D E B T$ were each highly significant and carried the same signs as reported in Table 3.

Appendix A

Footnote Disclosures Of Subsequent Adjustments Associated With Discretionary Disposals

Additional Write-Down Required

From Note 2 - Sheldahl Inc. - September 2, 1988.

On October 15, 1987, the Company announced its intention to divest Symbolic Displays, Inc. (SDI), a whollyowned subsidiary. Accordingly, a provision of $\$ 525,000$ net of tax benefits of $\$ 350,000$ was recorded in the fourth quarter of fiscal 1987 to reduce the carrying amount of the assets of the operation to the anticipated net realizable values and provide for other costs and expenses related to the divestiture. Based on an agreement to dispose of SDI, the Company determined, during the fourth quarter of 1988 , that an additional writedown of $\$ 528,000$ net of tax benefits of $\$ 352,000$ was necessary to state SDI's net assets at net realizable value. In the opinion of management, the provision for loss from discontinued operation is sufficient to cover costs related to the divestiture.

Reversal of a Portion of the Original Provision

From Note K - Concord Fabrics Inc. - August 30, 1987.

The Company decided to dispose of Eastern, its computer software subsidiary. In this connection, the statement of operations for the year ended August 31, 1986 included a $\$ 1,415,000$ provision (net of $\$ 1,205,000$ deferred tax benefit) for the estimated loss on disposal of this discontinued operation. During the year ended August 30, 1987, the disposal of this division was substantially completed and $\$ 432,000$ (net of $\$ 368,000$ income tax) of the aforementioned estimated loss was determined not to be required and has been reflected as a gain on disposal of discontinued division on the consolidated statement of operations for the year ended August 30, 1987.

No Adjustment to Loss Provision

From Note 10 - Alba-Waldensian Inc. - December 31, 1988.

In the fourth quarter of 1987, the Company announced it was discontinuing the operations of its Women's Fashion Sock Division. As a result, an estimated abandonment loss of $\$ 842,847$ was charged to 1987 net earnings. The settlement of all abandonment costs was completed during 1988 at a total cost not materially different from the 1987 estimate. 
Presentation of Discontinued Operations - Sheldahl, Inc.

\begin{tabular}{|c|c|c|c|}
\hline & 1988 & 1987. & $\underline{1986}$ \\
\hline Income From Continuing Operations & $\overline{\$ 544}$ & $\overline{\$ 2,465}$ & $\overline{\$ 505}$ \\
\hline \multicolumn{4}{|l|}{ Discontinued Operations: } \\
\hline \multicolumn{4}{|l|}{$\begin{array}{l}\text { Income (Loss) from operations, } \\
\text { net of tax benefit (provision) }\end{array}$} \\
\hline $\begin{array}{l}\text { Loss on divestiture, } \\
\text { including provision for } \\
\text { operating losses until } \\
\text { completion of divestiture, net } \\
\text { of tax benefit of } \$ 352,000\end{array}$ & (528) & $(1,200)$ & \\
\hline & & & \\
\hline Income (Loss) from discontinued operation & $(528)$ & $(1,788)$ & 114 \\
\hline Income before extraordinary gain & $\$ 16$ & $\$ 676$ & $\$ 620$ \\
\hline
\end{tabular}

Note 3:

On October 15, 1987, the Company announced its intention to divest Symbolic Displays, Inc. (SDI), a wholly-owned subsidiary. Accordingly, a provision of $\$ 525,000$ net of tax benefits of $\$ 350,000$ was recorded in the fourth quarter of fiscal 1987 to reduce the carrying amount of the assets of the operation to the anticipated net realizable values and provide fro other costs and expenses related to the divestiture. Based on an agreement to dispose of SDI, the Company determined, during the fourth quarter of 1988 , that an additional writedown of $\$ 528,000$ net of tax benefits of $\$ 352,000$ was necessary to state SDI's net assets at net realizable value. On the opinion of management, the provision for loss from discontinued operation is sufficient to cover costs related to the divestiture.

Net assets of SDI are included in the net assets of discontinued operation in the accompanying balance sheet. As of September 2, 1988, the balance includes net current assets of $\$ 2,299,000$, consisting primarily of inventories, accounts receivable and current liabilities plus non-current assets of $\$ 250,000$ consisting of property, plant and equipment which have been reduced to their estimated net realizable values.

Net sales for SDI were $\$ 6,871,000, \$ 9,094,000$ and $\$ 7,820,000$ for the fiscal years ended September 2, 1988, August 28, 1987 and August 31, 1986, respectively. 
Table 1

Sample Characteristics

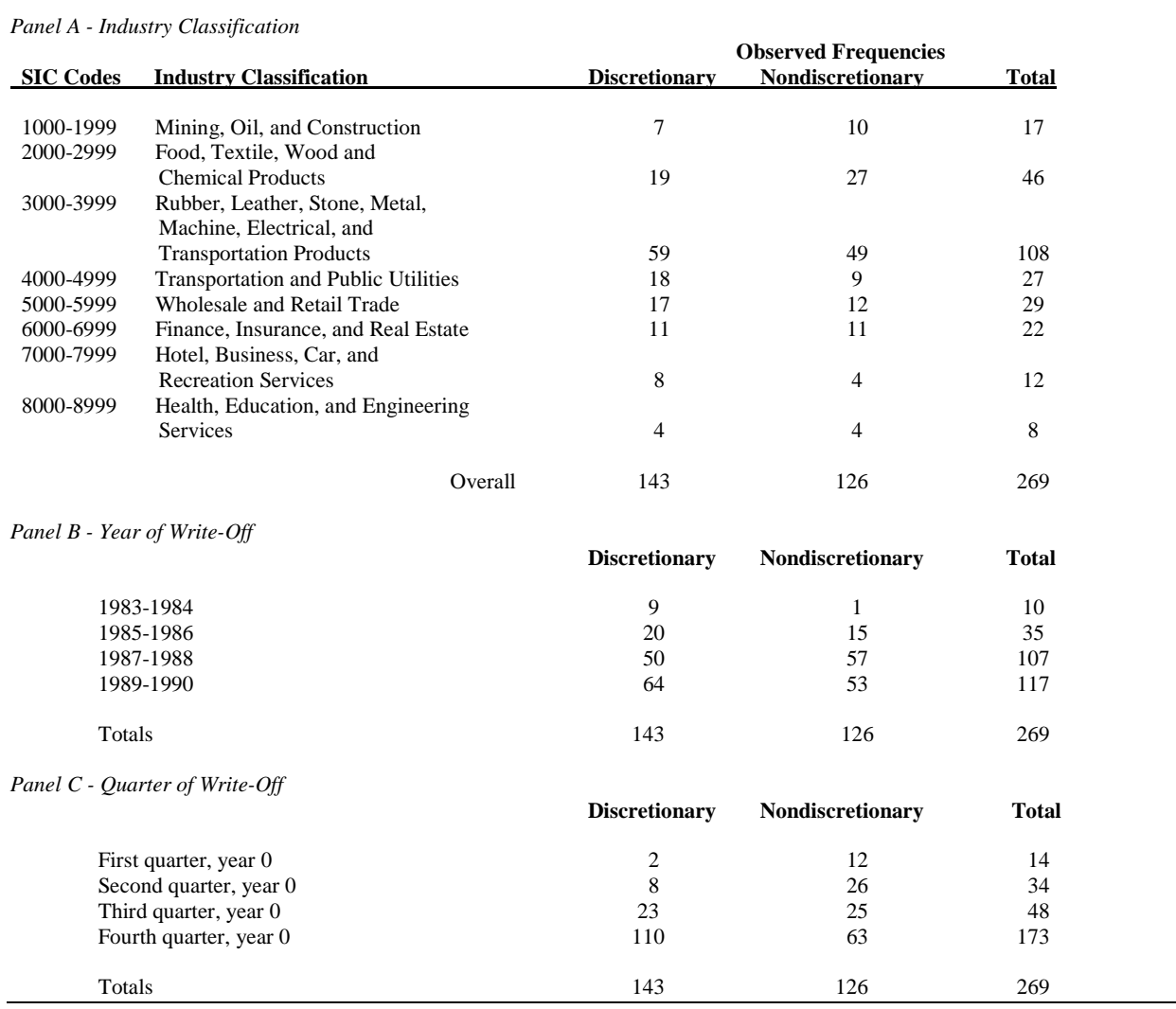


Table 2

Descriptive Statistics on Sample Firms

Panel A: Initial Provisions, Subsequent Adjustments, and Segment Earnings

Initial provision (\$ millions)

Initial provision to total assets

Subsequent adjustment (\$ millions)

Subsequent adjustment deflated by:

Firm total assets

Absolute value of initial provision Segment earnings:

$\begin{aligned} \text { Year }-2 & \text { - deflated by firm assets } \\ & \text { - deflated by segment sales }\end{aligned}$

Year -1 - deflated by firm assets - deflated by segment sales

Year 0 - deflated by firm assets - deflated by segment sales $\quad-1.055$

\begin{tabular}{|c|c|c|}
\hline \multicolumn{2}{|c|}{ Nondiscretionary } & $p$-value \\
\hline Mean & Median & for difference $^{\mathrm{a}}$ \\
\hline 16.871 & 0.000 & 0.000 \\
\hline 0.011 & 0.000 & 0.000 \\
\hline 2.891 & 0.000 & 0.002 \\
\hline 0.004 & 0.000 & 0.002 \\
\hline-0.175 & 0.000 & 0.049 \\
\hline 0.003 & 0.002 & 0.000 \\
\hline 0.012 & 0.022 & 0.000 \\
\hline-0.007 & 0.002 & 0.000 \\
\hline-0.044 & 0.014 & 0.000 \\
\hline-0.008 & 0.000 & 0.000 \\
\hline-0.084 & 0.005 & 0.000 \\
\hline
\end{tabular}

Panel B: Financial Characteristics of Sample Firms

Discretionary

Mean

$2,266.8$

$2,309.3$

$2,540.7$

$2,695.2$

$2,818.8$

$1,268.7$

$1,364.4$

$1,493.5$

$1,576.7$

$1,592.6$

0.028

0.023

$-0.007$

0.002

$-0.018$

0.584

0.608

0.687

0.708
0.717
Total assets (\$ millions): Year -2

Year -1

Year 0

Year +1

Year +2

Total revenues ( $\$$ millions):

Year -2

Year -1

Year 0

Year +1

Year +2

Return on assets (continuing): ${ }^{\mathrm{b}}$

Year -2

Year -1

Year 0

Year +1

Year +2

Total liabilities/Total assets

Year -2

Year -1

Year 0

Year +1

Year +2
Median

Proportion of firms reporting:

Above-the-line restructuring charges ${ }^{\mathrm{c}} \quad 0.203$

Changes in top management

0.406
181.4

193.6

195.7

182.3

169.5

149.5

163.3

185.2

198.5

220.8

0.036

0.035

0.014

0.023

0.023
0.024

0.581

0.589

0.666

0.671
0.655
Nondiscretionary $\quad p$-value Median for difference ${ }^{\mathrm{a}}$

$\begin{array}{lll}1,725.9 & 253.4 & 0.201 \\ 1,578.6 & 237.8 & 0.628 \\ 1,600.5 & 254.5 & 0.726 \\ 1,667.9 & 245.2 & 0.643 \\ 1,796.3 & 263.2 & 0.418 \\ & & \\ 1,076.8 & 180.4 & 0.915 \\ 1,153.2 & 195.1 & 0.895 \\ 1,233.8 & 215.4 & 0.829 \\ 1,259.5 & 278.9 & 0.911 \\ 1,323.4 & 278.9 & 0.998 \\ & & \\ 0.036 & 0.039 & 0.366 \\ 0.022 & 0.033 & 0.702 \\ 0.020 & 0.031 & 0.003 \\ 0.027 & 0.037 & 0.015 \\ 0.010 & 0.031 & 0.120 \\ & & \\ 0.558 & 0.571 & 0.662 \\ 0.558 & 0.559 & 0.224 \\ 0.563 & 0.569 & 0.000 \\ 0.558 & 0.546 & 0.000 \\ 0.573 & 0.601 & 0.001\end{array}$

$\begin{array}{lll}0.573 & 0.601 & 0.001\end{array}$

a - The reported $p$-values are associated with either the test of differences in medians or test of differences in proportions.

b - Return on assets is computed as (income from continuing operations/total assets).

c - Restructuring charges were separately reported as part of income from continuing operations

d - Management change is indicated if there was a change in any of the three top management positions in the firm (chairman of the board, chief executive officer, or president) in either year -1 or year 0 . 
Table 3

Probit Results for the Discretionary/Nondiscretionary Decision

\begin{tabular}{lcc}
\hline Predictor Variable & $\begin{array}{c}\text { Predicted } \\
\text { Sign }\end{array}$ & \multicolumn{1}{c}{$\begin{array}{c}\text { Estimated } \\
\text { Coefficient }^{\mathbf{a}}\end{array}$} \\
\cline { 2 - 3 } Intercept & $?$ & $-0.746(0.000)$ \\
$P R O V$ & - & $-10.998(0.000)$ \\
SEG & - & $-6.059(0.133)$ \\
SEE & - & $-6.032(0.029)$ \\
$Q T R$ & + & $0.873(0.000)$ \\
$M G M T$ & + & $-0.213(0.269)$ \\
$R E S T R$ & + & $0.288(0.301)$ \\
$I F C O$ & - & $-1.382(0.045)$ \\
)$I F C O$ & - & $-1.891(0.028)$ \\
LEV & + & $1.082(0.015)$ \\
& & $93.557(0.00)$ \\
Model $\Pi^{2}$ & & 0.252 \\
Likelihood ratio index & & 269 \\
Number of observations & & \\
\hline
\end{tabular}

a - The model is specified as follows:

$\left.\left.\operatorname{Pr}\left[D I S C R_{\mathrm{i}}=1\right]=\beta_{0}+\beta_{1} P R O V_{\mathrm{i}}+\beta_{2} S E G_{\mathrm{i}}+\beta_{3}\right) S E G_{\mathrm{i}}+\beta_{4} Q T R_{\mathrm{i}}+\beta_{5} M G M T_{\mathrm{i}}+\beta_{6} R E S T R_{\mathrm{i}}+\beta_{7} I F C O_{\mathrm{i}}+\beta_{8} \square\right) I F C O_{\mathrm{i}}+\beta_{9} L E V_{\mathrm{i}}+e_{\mathrm{i}}$

where $D I S C R_{\mathrm{i}}=1$ if firm $i$ reported a discretionary segment disposal, 0 otherwise;

$P R O V_{\mathrm{i}}=$ the initial provision on disposal reported by firm $i$, deflated by year 0 firm total assets

$S E G_{\mathrm{i}}=$ year 0 earnings of the discontinued segment for firm $i$, deflated by year 0 firm total assets;

)$S E G_{\mathrm{i}}=$ change in year 0 segment earnings from year -1 for firm $i$, deflated by year 0 firm total assets;

$Q T R_{\mathrm{i}} \quad=1$ if firm $i$ recognized the discontinuance of its segment in the fourth quarter of firm $i$ 's fiscal year, 0 otherwise;

$M G M T_{\mathrm{i}}=1$ if firm $i$ experienced a change in top management in either fiscal year 0 or fiscal year $-1,0$ otherwise;

$R E S T R_{\mathrm{i}}=1$ if firm $i$ also reported an "above-the-line" restructuring charge in year 0,0 otherwise;

$I F C O_{\mathrm{i}}=$ year 0 industry-adjusted continuing return on assets for firm $i$;

$I F C O_{\mathrm{i}}=$ change in year 0 industry-adjusted continuing return on assets from year -1 for firm $i$;

$L E V_{\mathrm{i}} \quad=$ industry-adjusted ratio of total liabilities to total assets for firm $i$; and

$e_{\mathrm{i}} \quad=$ error term

Numbers in parentheses represent the two-tailed $p$-values associated with the tests that the respective parameters differ significantly from zero. 
Table 4

Regression Results

\begin{tabular}{|c|c|c|c|}
\hline$\underline{\text { Predictor Variable }}$ & $\begin{array}{c}\text { Predicted } \\
\text { Sign } \\
\end{array}$ & $\begin{array}{c}\text { Discretionary } \\
\text { Discontinuances } \\
\text { Estimated } \\
\text { Coefficient }^{\mathrm{a}} \\
\end{array}$ & $\begin{array}{c}\text { Nondiscretionary } \\
\text { Discontinuances } \\
\text { Estimated } \\
\text { Coefficient }^{\mathrm{a}} \\
\end{array}$ \\
\hline Intercept & $?$ & $-0.023(.16)$ & $0.033(.10)$ \\
\hline PROV & - & $-0.381(.00)$ & $0.007(.93)$ \\
\hline$S E G$ & + & $0.892(.00)$ & $-0.125(.24)$ \\
\hline )SEG & - & $-0.125(.13)$ & $0.083(.62)$ \\
\hline PER & - & $-0.032(.01)$ & ---- \\
\hline PER $x$ SEG & + & $-0.492(.00)$ & ---- \\
\hline UNCERT & $?$ & --- & $0.050(.00)$ \\
\hline UNCERT X SEG & + & ---- & $0.632(.04)$ \\
\hline$M G M T$ & + & $0.054(.00)$ & $-0.001(.91)$ \\
\hline IFCO & + & $0.186(.00)$ & $0.011(.92)$ \\
\hline$D E C L$ & - & $-0.215(.00)$ & $0.130(.28)$ \\
\hline$I M P R$ & + & $0.426(.00)$ & $-0.018(.77)$ \\
\hline FUTURE & + & $0.205(.00)$ & $0.030(.74)$ \\
\hline$L E V$ & - & $-0.025(.21)$ & $-0.079(.01)$ \\
\hline$D E B T$ & + & $-0.029(.33)$ & $-0.024(.37)$ \\
\hline$L E V \times D E B T$ & + & $0.052(.16)$ & $0.067(.22)$ \\
\hline \multicolumn{2}{|l|}{ Model $\Pi^{2}$} & $487.56(.00)$ & $24.67(.03)$ \\
\hline \multicolumn{2}{|l|}{ Adjusted $R^{2}$} & 0.669 & 0.272 \\
\hline \multicolumn{2}{|c|}{ Wald test of joint significance of firm-level variables $\left(\Pi^{2}\right)$} & $94.61(.00)$ & $12.32(.14)$ \\
\hline \multicolumn{2}{|c|}{ Number of observations } & 142 & 125 \\
\hline
\end{tabular}

a - The models are more explicitly described in the paper. Results reported in the table were obtained using weighted least-squares. Two-tailed $p$-values based on White (1980) $t$-statistics are reported in parentheses in the table, and the White estimate of the covariance matrix is used to test the significance of the overall model and of the firm-level variables. OLS analyses of the discretionary and nondiscretionary disposals using the White (1980) estimator of the covariance matrix with unspecified

heteroskedasticity yielded results that were similar to those reported in the table (see the text of the paper for a discussion). 


\section{NOTES}

Formatted: Font: Bold

Formatted: Centered 


\section{Endnotes}

1. Adjustments can represent either additional loss accruals or reversals of accruals. Moehrle (2002) identified a total of only 114 firms announcing reversals of restructuring charges over the period from 1990 to 1999 , and of these was able to use only 83 or 121 firm-quarters in his analysis (depending on modeling approach). Elliott and Shaw identified only one out of 240 firms disclosing a reversal. On the other hand, Elliott and Hanna (1996) document that 27 percent of firms taking write-offs in one year also recognize another write-off in the subsequent year, although they do not report whether the subsequent write-off represented an adjustment to the initial write-off.

2. APB 30 has been superceded by SFAS 144, Accounting for the Impairment or Disposal of Long-Lived Assets, which was issued in August 2001 and is effective for financial statements issued for fiscal years beginning after December 15, 2001. The revisions to the accounting standards for segment disposals are discussed in accompanying footnotes.

3. In contrast, SFAS 144 now requires firms to exclude from the estimates of the initial provision any estimated segment operating performance during the anticipated disposal period, and instead disclose (as part of income from discontinued operations) the disposal period operating results when realized. Discussion underlying the decision focused on the notion that any estimated operating losses during the period did not meet the definition of a liability.

4. SFAS 144 continues these requirements.

5. In a number of cases, a firm discontinued more than one segment in a given accounting year. Such firms were included in the discretionary sample if aggregated earnings for the portfolio of segments was disclosed and if the transaction was not essentially completed. The transaction was considered essentially complete if disposal of a majority of the portfolio was accomplished by the time the financial statements are issued.

6. Examples of inadequate or insufficient disclosure included segment earnings not separately disclosed, commingled segment earnings for successive write-offs, subsequent adjustments that were not associated with a particular write-off, information on other model variables not available.

7. Most firms recorded such adjustments in the accounting period subsequent to the write-off period. However, a few of the sampled firms recorded multiple adjustments; i.e., adjustments were made in both of the periods following the write-off. In such cases, the net amount of the two adjustments was the amount recorded. Each of these firms recorded overall additions to the initial write-off provision, while none recorded overall reversals of the initial provisions.

8. This result is not necessarily surprising. To the extent that managers are only able estimate a range of possible loss provisions and are unable to choose a loss in that range, then SFAS 5 (FASB 1975) requires managers to accrue the smaller of the two amounts and to disclose the greater of the two amounts. If managers systematically accrue a lower limit, then adjustments are likely to be biased downward. Interestingly, however, no firm in our sample disclosed upper and lower limits on the range.

9. In a number of cases, even though the disposal was recognized in the fourth quarter according to a firm's annual report, the actual announcement occurred after the close of the firm's fiscal year, so that the announcement actually occurred in the first quarter of the following year. This was observed for 21 of the 143 discretionary disposals and 15 of the 126 nondiscretionary disposals.

10. Rapaciolli and Schiff (1991) document a tendency of firms to disclose disposal losses below income from continuing operations, while disposal gains tend to be reported as part of continuing operations. Loh et al. (2001) report similar results. However, as far as we could tell, neither paper makes a distinction between what we characterize as discretionary and nondiscretionary segment disposals.

11. Consistent with APB 30 constraining the ability of firms to recognize gains on disposal prior to realization, none of the discretionary adopters recognized an initial estimated gain on disposal.

12. Diagnostics suggested the use of heteroskedastic probit analysis. Qualitatively similar parameter estimates were obtained and similar statistical inferences were made when using standard probit analysis with robust standard errors.

13. Somewhat weaker results on the measures of continuing performance are obtained when unadjusted earnings and leverage 
measures are used in the regression.

14. Only a very few firms required disposal periods in excess of two years and these were primarily in the insurance and real estate industries.

15. It may be that the initial loss estimate may be subject to less scrutiny by the firm's external auditors because of the below-theline treatment of the write-off, and because management's representations of the earnings effect of the write-off may have seemed reasonable at the time. Additional information that becomes available during the disposal period may lead to doubts about the realizability of the restated asset values.

16. Since segment disposals are presented below income from continuing operations, managers' manipulation of the initial provision would have direct effects on net income rather than on continuing earnings. If continuing earnings are the basis for bonus calculations, managers would have little incentive to manipulate initial provisions, unless the manipulation could somehow affect continuing earnings. However, Gaver, Gaver, and Austin (1995) document that results of discontinued operations are rarely excluded from the earnings definition used for bonus determination. There is also evidence that nonrecurring items flow through the compensation function (e.g., Gaver and Gaver 1998; Defeo, Lambert, and Larcker 1989; Healy, Kang, and Palepu 1987), while other research suggests that executive compensation is shielded from nonrecurring charges (Dechow, Huson and Sloan 1995).

17. We also measured unexpectedly good earnings in a manner consistent with Francis et al. (1996). Specifically, unexpectedly good performance is defined as positive values of UROA in excess of the amount of the initial provision. We obtained results that were virtually identical to those reported in Table 4.

18. Unlike the discretionary disposals, we would not expect the firm to attempt to impose operating efficiencies on a segment for which a contract for sale exists. How the segment is operating up to the measurement date is therefore likely to continue during any delay in closing that might arise from the existing uncertainty. Therefore, we believe the positive association can be predicted unambiguously.

19. Specifically, when the model included industry indicators, $L E V, D E B T$, and $L E V \times D E B T$ were not significant at conventional levels. When the model included year indicators, $L E V, D E B T$, and $L E V \times D E B T$ were each highly significant and carried the same signs as reported in Table 3. 